\section{Decreased expression of Met during differentiation in rat lung}

\author{
T. Kato, ${ }^{1,2,3}$ K. Oka, ${ }^{4}$ T. Nakamura, ${ }^{4}$ A. Ito \\ 'Department of Pharmacology, Faculty of \\ Medicine, Kinki University, Osaka \\ 2Department of Pathology, Faculty of \\ Medicine, Kinki University, Osaka \\ ${ }^{3}$ Division for Regenerative Drug \\ Discovery, Center for Advanced Science \\ and Innovation, Osaka University \\ ${ }^{4}$ Research \& Development, Neurogen Inc., \\ Osaka, Japan
}

\section{Abstract}

Organ-specific stem cells play key roles in maintaining the epithelial cell layers of lung. Bronchioalveolar stem cells (BASCs) are distal lung epithelial stem cells of adult mice. Alveolar type 2 (AT2) cells have important functions and serve as progenitor cells of alveolar type 1 (AT1) cells to repair the epithelium when they are injured. Hepatocyte growth factor (HGF) elicits mitogenic, morphogenic, and anti-apoptotic effects on lung epithelial cells through tyrosine phosphorylation of Met receptor, and thus is recognized as a pulmotrophic factor. To understand which cells HGF targets in lung, we identified the cells expressing Met by immunofluorescence assay. Met was strongly expressed in BASCs, which expressed an AT2 cell marker, pro-SP-C, and a club cell marker, CCSP. In alveoli, we found higher expression of Met in primary AT2 than in AT1 cells, which was confirmed using primary AT2 cells. We further examined the mitogenic activity of HGF in AT2-cell-derived alveolar-like cysts (ALCs) in 3D culture. Multicellular ALCs expressed Met, and HGF enhanced the ALC production. Taking these findings together, BASCs could also be an important target for HGF, and HGF-Met signaling could function more potent on cells that have greater multipotency in adult lung.

\section{Introduction}

Lung epithelial repair is dependent on stem/progenitor cell populations in distinct niches along the proximal-distal axis. ${ }^{1-3}$ Crosstalk between lung stem/progenitor cells and their niche is likely to be pivotal for maintaining the balance of stem and differentiated cells. Defects in such interactions may lead to acute respiratory distress syndrome, chronic obstructive pulmonary disease, idiopathic pulmonary fibrosis, and cancer. Bronchioalveolar stem cells (BASCs) are adult murine distal lung epithelial stem cells that reside in the bronchioalveolar duct junction (BADJ), which is localized between the conducting and respiratory epithelium in terminal bronchiole. Lineage-tracing analyses showed that BASCs could give rise to club cells and alveolar epithelial cells in vivo.,4 The squamous alveolar type 1 (AT1) cells cover $90 \%$ of the alveolar space area and are essential for normal gas exchange. The cuboidal alveolar type 2 (AT2) cells are larger in number than AT1 cells, but AT2 cells occupy only $5 \sim 10 \%$ of the surface area. ${ }^{5}$ AT2 cells have multiple functions, including in surfactant production and secretion. ${ }^{6}$ When AT1 cells are damaged, adjacent AT2 cells are stimulated to proliferate and transdifferentiate into AT1 cells. ${ }^{6}$

Hepatocyte growth factor (HGF) was identified and cloned as a factor inducing the proliferation of adult rat hepatocytes. ${ }^{7}$ Plasma and local HGF levels increase in response to lung injury under pathological conditions. ${ }^{7}$ HGF exerts mitogenic, morphogenic and anti-apoptotic effects on lung epithelial cells. These multiple functions are exerted through tyrosine phosphorylation of Met, a receptor for HGF. $^{8,9}$ The selective inhibition of Met signaling by anti-HGF antibody leads to the exacerbation of lung injury, identifying endogenous HGF as a pulmotrophic factor. ${ }^{7}$

Met expression has been reported to correlate with proliferation and anti-apoptosis in non-small cell lung cancer. ${ }^{10,11}$ However, it is not clear what cells in lungs are targeted by the HGF-Met signal, and we thus aimed to characterize Met expression in adult normal lung.

\section{Materials and Methods}

\section{Isolation, purification, and culture of rat alveolar type II epithelial cells}

Experiments with animals were performed in accordance with the Guide for Animal Experiments of Osaka University and the Committee of Research Facilities for Laboratory Animal Sciences, Osaka University. AT2 epithelial cells were isolated from specific pathogen-free Sprague-Dawley male rats weighing $150-250 \mathrm{~g}$, as previously reported ${ }^{12}$ with slight modification. We treated the lung with elastase $(10 \mathrm{U} / \mathrm{mL})$ (Nacalai tesque, Kyoto, Japan)/collagenase $(0.1 \mathrm{mg} / \mathrm{mL})$ (Wako, Osaka, Japan) solution for the dissociation of cells. Furthermore, we suspended the obtained cells in D-MEM/F12 containing 10\% FBS, 100 $\mathrm{U} / \mathrm{mL}$ penicillin, $100 \mathrm{~g} / \mathrm{mL}$ streptomycin, 50 $\mathrm{g} / \mathrm{mL}$ gentamycin, and $0.25 \mathrm{~g} / \mathrm{mL}$ fungizone.
Correspondence: Dr. Takashi Kato, Department of Pharmacology, Faculty of Medicine, Kinki University, 377-2 Ohno-higashi, Osakasayama, Osaka 589-8511, Japan.

Tel. +81.72.366-0221 - Fax: +81.72.367-1820.

E-mail: t-kato@med.kindai.ac.jp

Key words: HGF; Met; BASC; alveolus; ALC.

Contributions: TK, experiments performing, manuscript drafting; KO, TN, AI, supervision and discussion of the study.

Acknowledgments: we thank Mr. Mori for technical assistances. This work was supported by a grant from the Ministry of Education, Culture, Sports, Science, and Technology of Japan (No. 14454911 to TK)

Conflicts of interest: the authors declare no conflict of interest.

Received for publication: 12 0ctober 2015. Accepted for publication: 5 January 2016.

This work is licensed under a Creative Commons Attribution-NonCommercial 4.0 International License (CC BY-NC 4.0).

(C) Copyright T. Kato et al., 2016

Licensee PAGEPress, Italy

European Journal of Histochemistry 2016; 60:2575 doi:10.4081/ejh.2016.2575

3D culture of rat alveolar type II epithelial cells

To produce ALC, the freshly isolated primary AT2 cells were harvested at $1 \times 10^{5}$ cells $/ \mathrm{cm}^{2}$ in D-MEM/F12 supplemented with 10\% FBS and $2 \%$ growth factor-reduced Matrigel on Matrigel-coated chambers (BD Biosciences, Bedford, MA, USA) as previously reported..$^{13}$ Ten and $50 \mathrm{ng} / \mathrm{mL}$ recombinant human HGF (rhHGF) was added at the beginning of 3D-cultures for AT2 cells (Day 0). The media with rhHGF was changed every 3 days.

\section{Immunostaining assay of Met in normal rat lungs}

Lungs removed at each autopsy were fixed in cold 10\%-buffered formalin for $24 \mathrm{~h}$, and were then subjected to a routine process for paraffin embedding. Anti-Met IgG [sc-8057; Santa Cruz Biotechnology (SCB), Dallas, TX, USA], antisurfactant protein-C pro-peptide (pro-SP-C) IgG (AB3786; Chemicon Int., Temecula, CA, USA), anti-AQP-5 IgG (sc-26828; SCB), and anti-CCSP IgG (sc-9772; SCB) were used. First antibodies are used in the dilution as 1:200 and normal IgG were used as control antibodies respectively. Antigen retrieval was performed by using $1 \mathrm{mM}$ EDTA at pH 8.0 in a microwave for $20 \mathrm{~min}$ for staining. For immunofluorescence staining 
assay, the sections were incubated at $4^{\circ} \mathrm{C}$ overnight. Subsequently washed with PBS, and the sections were then incubated with secondary antibodies (1:600, Alexa488-, Alexa546-, and Alexa647-conjugated IgG; Life technologies, CA, USA) at room temperature for $20 \mathrm{~min}$. After washed with PBS, the sections were mounted with crystal mount (Biomeda, Foster City, CA, USA) and observed under an LSM5 PASCAL confocal microscope (Carl Zeiss AG, Jena, Germany).

mRNA expression in primary alveolar cells

Quantitative reverse transcription-polymerase chain reaction (qRT-PCR) was performed as described previously. ${ }^{14}$ The following specific primers were used for rat $c-M e t, S P-A$, SP-C, RTI, caveolin, and GAPDH: c-Met Forward 5'-CAG ACG CCT TGT ATG AAG T-3', $c$ Met Reverse 5'-CAT AAG TAG CGT TCA CAT GG3'; SP-A Forward 5'-TAC CAG AGA GGA GGC AAC A-3', SP-A Reverse 5'-CAA TAC TTG CAA TGG CCT CGT T-3'; $S P$ - $C$ Forward 5'-GTG GTT GTG GTG GTA GTC CTT G-3', $S P$ - $C$ Reverse 5'TAG CAG TAG GTT CCT GGA GGA GGT G-3' RTI Forward 5'-GCC ATC GGT GCG CTA GAA GAT GAT CTT-3' RTI Reverse 5'-GTG ATC GTG GTC GGA GGT TCC TGA GGT-3'; caveolin Forward 5'-CAG CAT GTC TGG GGG TAA AT-3', caveolin Reverse 5'-TGC TTC TCA TTC ACC TCG TCT-3'; GAPDH Forward 5'-CCT GTG ACT TCA ACA GCA ACT C-3', GAPDH Reverse 5'-ACC CTG TTG CTG TAG CCA TAT T-3'.

\section{Statistical analysis}

The student's $t$-test was performed to evaluate the significant differences of each group.

\section{Results}

Met expression in BASCs and alveolar type II cells

We first performed immunohistochemical assay into adult rat lung, and found Met expression at the BADJ region (Figure 1A; Supplementary Figure 1A). We further identified the expressing cells by immunofluorescence staining. BASCs are known to coexpress a bronchiolar club marker, club cell secretory protein (CCSP), and an AT2 cell marker, prosurfactant protein C (pro-SP-C). ${ }^{15}$ Therefore, to confirm the strong expression of Met in BASCs, we performed immunofluorescence analysis of Met with pro-SP-C and CCSP (Figure 1B; Supplementary Figure 1B). As shown in Figure 1B, Met was strongly expressed in BASCs. Next, we focused on Met expression in alveoli. While AT2 cells express pro-surfactant proteins $\mathrm{A}, \mathrm{B}$, and $\mathrm{C}$, alveolar type I cells (AT1) express aquaporin-5 (AQP-
5), RTI, and caveolin. ${ }^{16-19}$ To verify the Met expression in AT2 cells, we performed immunofluorescence assays of Met with proSP-C (Figure 2A). This merged image shows the Met expression in AT2 cells. On the other hand, we examined the Met expression in AT1 cells by immunofluorescence staining with $\mathrm{AQP}-5$ (Figure 2B). In contrast to pro-SP-C, the staining of Met was not co-localized with AQP5 . Thus, AT1 cells did not abundantly express Met.
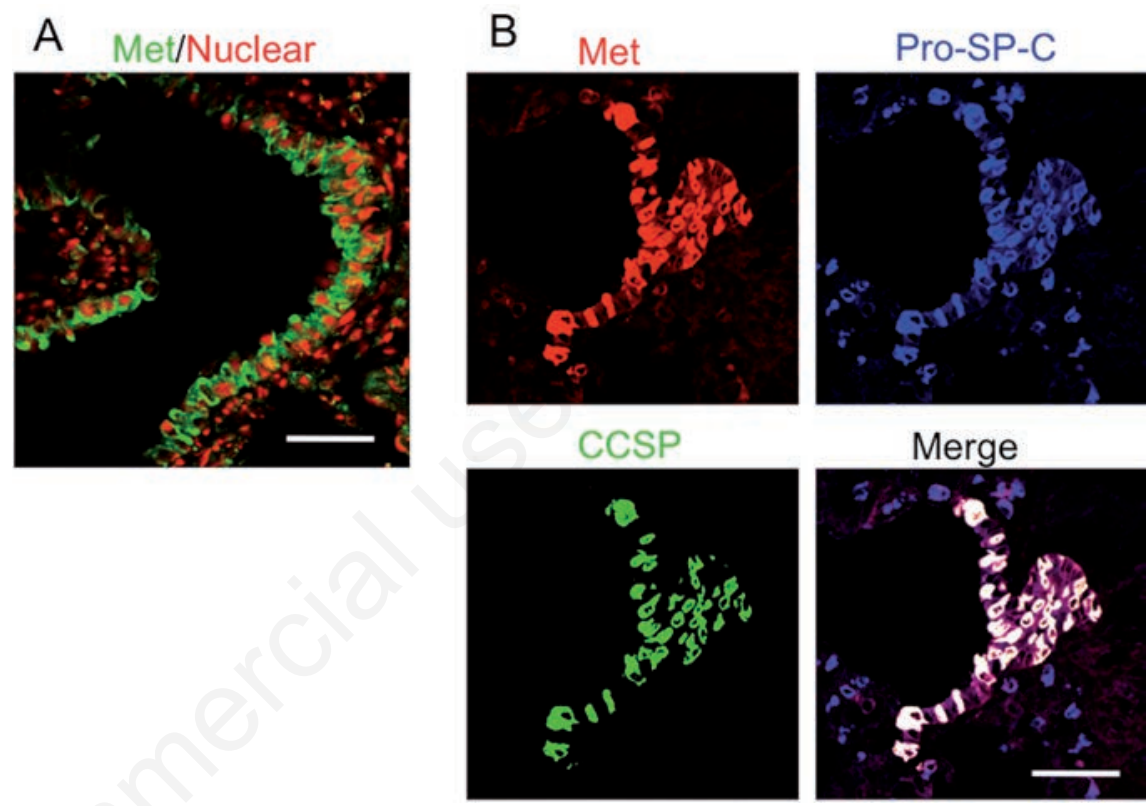

Figure 1. Immunofluorescence assay for Met expression of BASCs in adult rat lung. A) Met (green) was merged with nuclei as PI (red). B) Met (red) merged with pro-SP-C (blue) and CCSP (green) in adult normal lung. Scale bars: $50 \mu \mathrm{m}$.
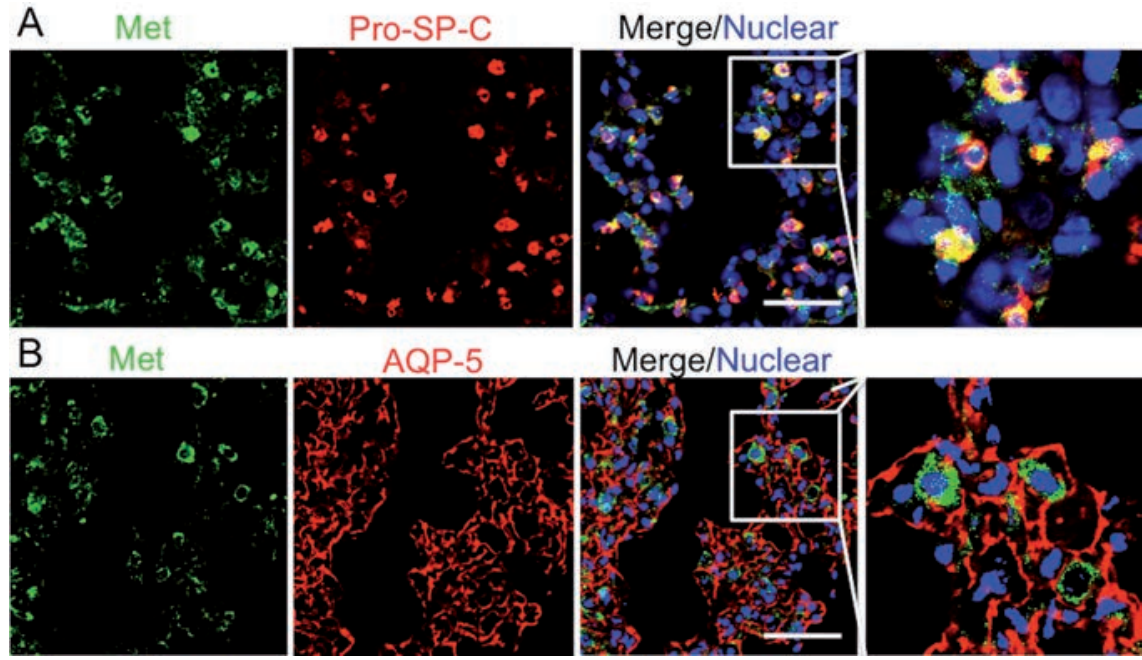

AQP-5
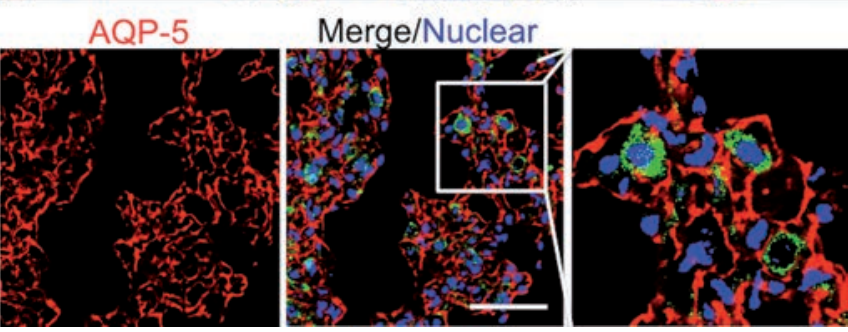

Figure 2. Met expression in alveoli of normal adult rat. A) Met (green) merged with proSP-C (red). B) Met (green) merged with AQP-5 (red). Scale bars: $50 \mu \mathrm{m}$. 
observed their morphology. We determined a phase-contrast micrograph of rat alveolar epithelial cells cultured for 2 days after seeding the isolated AT2 cells. The cells were cuboidal in shape, and had lamellar bodies, a characteristic feature of AT2 cells, inside them (Figure 3A). Furthermore, we exhibited the cell morphology after culturing for 6 days (Figure 3A). The cells became flattened and were squamous in shape, and possessed practically no lamellar bodies, as recognized in the lung AT1 cells. In order to confirm these cells, the expression of marker genes for AT1 and AT2 cells was examined using real-time RTPCR analysis. The mRNA expression levels of type I cell markers, RTI and caveolin, were higher in the 6 days-cultured cells than in the 2 days-cultured ones (Table 1). In contrast, the mRNA expression levels of AT2 cell markers, surfactant proteins- $A$ and $-C$, were lower in the 6 day-cultured cells than in the 2 day-cultured ones (Table 1). Thus, we examined the difference of Met mRNA between the 6 day-cultured cells and the 2 day-cultured ones. Met mRNA expression in the 2 day-cultured cells was 5.8fold higher than that in the normal adult lung, and the expression in the 6 day-cultured cells was at the same level as in the adult lung (Figure 3B). We confirmed this Met decrease in primary AT2 cells by immunofluorescence. The primary cultured AT2 cells expressed Met after 2 days of culture, but exhibited decreased Met expression after 6 days of culture (Figure $3 \mathrm{C})$.

\section{HGF enhances alveolar-like cysts in 3D culture}

It was previously reported that HGF induces the proliferation of primary AT2 cells under monolayer culture. In the present study, we examined the mitogenic activity of HGF into AT2 cells-derived alveolar-like cysts (ALCs) in 3D culture. ALCs have been generated according to a reported method. ${ }^{13}$ After 8 days of culture, multicellular ALCs formed (Figure 4A) and expressed pro-SP-C, which indicated that ALCs maintained AT2 cell characteristics (Figure 4B). At 8 days culture, ALCs exhibited Met expression (Figure 4C). HGF increased the total number of ALCs (Figure 4D) and the number of ALCs with a $50-\mu \mathrm{m}$ diameter (Figure 4E). Therefore, HGF enhanced the ALC production.

\section{Discussion}

During lung injuries in rodents, mRNA and protein levels of HGF markedly increased within $24 \mathrm{~h}$ after challenge, followed by inducing the proliferation of lung alveolar and bronchial epithelium. ${ }^{21}$ Previous studies have revealed
Table 1. Expression of AT1 and AT2 cell type markers.

\begin{tabular}{lccc} 
Gene & Day 2 & Day 6 & Ratio (day 6/days 2) \\
RTI40 & $0.57+/-0.06$ & $1.94+/-0.50$ & $3.41^{*}$ \\
Caveolin-I & $0.24+/-0.03$ & $1.97+/-0.21$ & $8.21^{*}$ \\
\hline$S P-A$ & $0.86+/-0.11$ & $0.29+/-0.01$ & $0.33^{*}$ \\
$S P-B$ & $1.13+/-0.13$ & $0.43+/-0.05$ & $0.38^{*}$ \\
\hline
\end{tabular}

Each value represents the mean+/-SE $(\mathrm{n}=4)$ of relative expression level normalized by GAPDH (compared with adult rat lung); $* \mathrm{P}<0.05$.

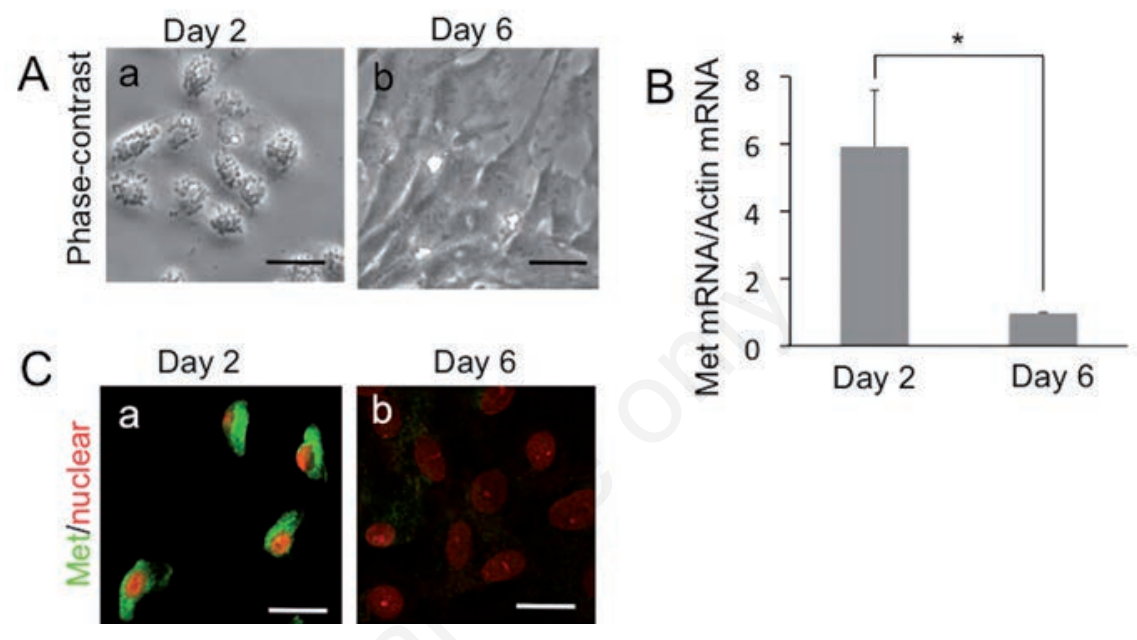

Figure 3. Met expression in the primary alveolar cells. A) Phase-contrast image of isolated AT2 cell after 2 days (a) and 6 days of culture (b). B) Change of Met mRNA in isolated AT2 cells during culture; each value represents the mean +/- SD of the relative expression level normalized by GAPDH; $\mathbf{n}=3$ for each group; each sample was examined by duplicate and averaged; ${ }^{*} \mathrm{P}<\mathbf{0 . 0 5}$. C) Change of Met protein (green) in isolated AT2 cells during culture; (a) Cultured for 2 days; (b) Cultured for 6 days; nuclei were stained with PI (red). Scale bars: $10 \mu \mathrm{m}$.
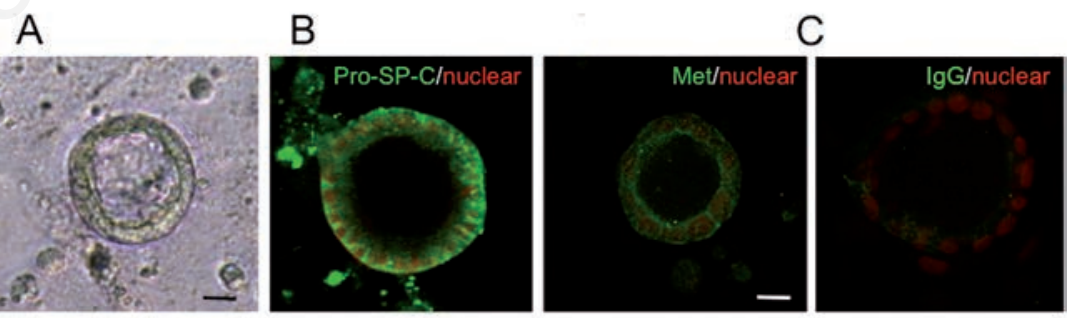

D
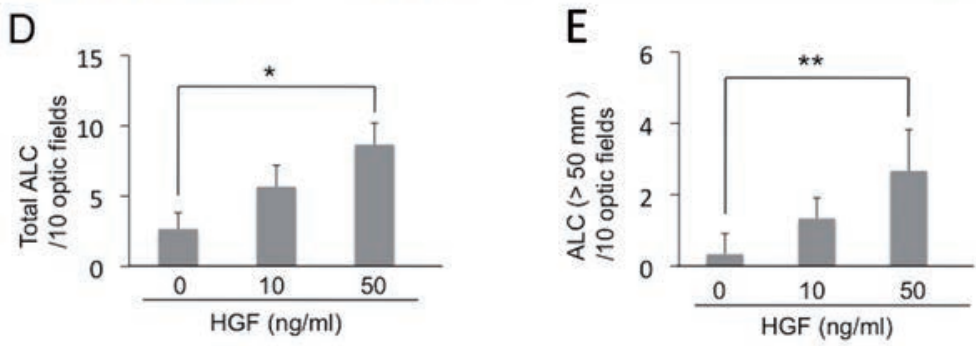

Figure 4. HGF enhances the formation of ALCs. A) Phase-contrast pictures after 8 days in $2 \%$ Matrigel culture. B,C) Immunofluorescence staining of Pro-SP-C (B) and Met (C) as green; nuclei were stained with PI (red). D) Total number of ALCs after 8 days of cultures with rHGF. E) Number of ALCs with a diameter larger than $50 \mu \mathrm{m}$ after 8 days of cultures with rHGF $(n=3)$. ${ }^{*} \mathbf{P}<0.05 ;{ }^{* *} \mathbf{P}<\mathbf{0 . 0 1}$. Scale bars: $10 \mu \mathrm{m}$. 
that HGF enhances the proliferation of AT2 cells and their migration on the provisional matrix proteins. ${ }^{7}$ The present study suggests that BASCs could also be an important target for HGF. However, it remains unknown what functions HGF exert on BASCs during lung injury, and further studies are required to confirm that Met phosphorylation in BASCs of damaged lungs. Since BASCs are resistant to lung injury and proliferate to restore the epithelium, ${ }^{15,22}$ HGF could play important roles in the mitogenic and anti-apoptotic activities of BASCs. Furthermore, HGF also has morphological activities in the epithelium. HGF induces branching tubulogenesis in renal epithelial cells $s^{23}$ and regulates epithelial development and morphogenesis in different organs including lung. The development of lung epithelia is inhibited by neutralizing HGF or the use of an antisense strategy in organ cultures of the developing lung. ${ }^{24}$ Recently, we found the HGF-Met signal is essential for morphogenesis of bronchioalveolar structure using the human transformed bronchial epithelial (HBE135) cells in 3D culture. ${ }^{25}$ This epithelial cell line was established from human bronchial epithelium and expresses CCSP and pro-SP-C, thus we guess the cells are derived from BASCs in BADJ. Lee et al. isolated primary BASCs and observed the bronchioalveolar colonies under clonal 3D culture system. ${ }^{26}$ To deepen our understanding, it is important to assess the HGF-Met signal for morphogenesis in the 3D culture using isolated primary BASCs.

HGF might act as a potent multifunctional pulmotrophic factor that induces the formation of alveolar networks from destroyed alveolar cells in injured tissues. ${ }^{27,28}$ In lung alveoli, there is evidence from injury models that AT2 cells can proliferate and give rise to AT1 cells. Because AT1 cells showed little expression of Met, HGF-Met signaling does not protect AT1 cells from harmful particles from the air space, but rather acts on multipotent cells during alveolar regeneration. Selective deletion of the c-met gene in AT2 cells leads to malformation of alveolar septae. ${ }^{29}$ Taken together, HGF is an indispensable cytokine for AT2 cells. HGF is known to enhance the proliferation of primary AT2 cells under monolayer culture. However, primary AT2 cells easily tend to differentiate into AT1-like cells, and it is difficult to maintain AT2 cells in culture. Several mammary cell lines also form cysts when grown in 3D ECM gel. By culturing human primary AT2 cells in Matrigel, the cells formed ALC, lined by a polarized monolayer of cells, which retained specific AT2 properties. ${ }^{13}$ In the present study, we found that HGF also enhanced the growth of ALC, and had mitogenic activities in AT2 cells, even in a 3D culture system.

In summary, HGF-Met signaling is well known as a pulmotrophic factor, but the target cells has not been clearly identified. The present study reveals that HGF receptor Met is highly expressed in BASCs. In alveoli, AT2 cells exhibited higher levels of Met than AT1 cells, and HGF enhanced the proliferation of AT2 cells in 3D culture. Taking these findings together, HGF-Met systems could tightly function on cells that have greater multipotency in adult lungs.

\section{References}

1. Otto WR. Lung epithelial stem cells. J Pathol 2002;197:527-35.

2. Rawlins EL, Okubo T, Xue Y, Brass DM, Auten RL, Hasegawa H, et al. The role of Scgblal+ Clara cells in the long-term maintenance and repair of lung airway, but not alveolar, epithelium. Cell Stem Cell 2009;4:525-34.

3. Rock JR, Barkauskas CE, Cronce MJ, Xue Y, Harris JR, Liang J, et al. Multiple stromal populations contribute to pulmonary fibrosis without evidence for epithelial to mesenchymal transition. Proc Natl Acad Sci USA 2011;108:E1475-83.

4. Tropea KA, Leder E, Aslam M, Lau AN, Raiser DM, Lee JH, et al. Bronchioalveolar stem cells increase after mesenchymal stromal cell treatment in a mouse model of bronchopulmonary dysplasia. Am J Physiol Lung Cell Mol Physiol 2012;302:L829-37.

5. Patton JS. Mechanisms of macromolecule absorption by the lungs. Adv Drug Deliv Rev 1996;19:3-36.

6. Fehrenbach H. Alveolar epithelial type II cell: defender of the alveolus revisited. Respir Res 2012;2:33-46.

7. Nakamura T, Mizuno S. The discovery of hepatocyte growth factor (HGF) and its significance for cell biology, life sciences and clinical medicine. Proc Jpn Acad Ser B Phys Biol Sci 2010;86:588-610.

8. Bottaro DP, Rubin JS, Faletto DL, Chan AM, Kmiecik TE, Vande Woude GF, et al. Identification of the hepatocyte growth factor receptor as the c-met proto-oncogene product. Science 1991;251:802-4.

9. Higuchi 0, Mizuno K, Vande Woude GF, Nakamura T. Expression of c-met protooncogene in COS cells induces the signal transducing high-affinity receptor for hepatocyte growth factor. FEBS Lett 1992;301:282-6.

10. Sun C, Liu Z, Li S, Yang C, Xue R, Xi Y, et al. Down-regulation of c-Met and Bcl2 by microRNA-206, activates apoptosis, and inhibits tumor cell proliferation, migration and colony formation. Oncotarget 2015;6:25533-74.
11. Sun C, Sang M, Li S, Sun X, Yang C, Xi Y, et al. Hsa-miR-139-5p inhibits proliferation and causes apoptosis associated with down-regulation of c-Met. Oncotarget 2015;6:39756-92.

12. Ikehata M, Yumoto R, Nakamura K, Nagai J, Takano M. Comparison of albumin uptake in rat alveolar type II and type I-like epithelial cells in primary culture. Pharm Res 2008;25:913-22.

13. Yu W, Fang X, Ewald A, Wong K, Hunt CA, Werb Z, et al. Formation of cysts by alveolar type II cells in three-dimensional culture reveals a novel mechanism for epithelial morphogenesis. Mol Biol Cell 2007;18: 1693-700.

14. Kato T, Funakoshi H, Kadoyama K, Noma S, Kanai M, Ohya-Shimada W, et al. Hepatocyte growth factor overexpression in the nervous system enhances learning and memory performance in mice. $\mathrm{J}$ Neurosci Res 2012;90:1743-55.

15. Kim CF, Jackson EL, Woolfenden AE, Lawrence S, Babar I, Vogel S, et al. Identification of bronchioalveolar stem cells in normal lung and lung cancer. Cell 2005;121:823-35.

16. Campbell L, Hollins AJ, Al-Eid A, Newman GR, von Ruhland C, Gumbleton M. Caveolin-1 expression and caveolae biogenesis during cell transdifferentiation in lung alveolar epithelial primary cultures. Biochem Biophys Res Commun 1999;262: 744-51.

17. Clegg GR, Tyrrell C, McKechnie SR, Beers MF, Harrison D, McElroy MC. Coexpression of RTI40 with alveolar epithelial type II cell proteins in lungs following injury: identification of alveolar intermediate cell types. Am J Physiol Lung Cell Mol Physiol 2005;289:L382-90.

18. Delgado 0, Kaisani AA, Spinola M, Xie XJ, Batten KG, Minna JD, et al. Multipotent capacity of immortalized human bronchial epithelial cells. PLoS One 2011;6:e22023.

19. Banerjee ER, Henderson WR Jr. Characterization of lung stem cell niches in a mouse model of bleomycin-induced fibrosis. Stem Cell Res Ther 2012;3:21.

20. Dobbs LG. Isolation and culture of alveolar type II cells. Am J Physiol 1990;258:L134-47.

21. Yanagita K, Matsumoto K, Sekiguchi K, Ishibashi $\mathrm{H}$, Niho Y, Nakamura T. Hepatocyte growth factor may act as a pulmotrophic factor on lung regeneration after acute lung injury. J Biol Chem 1993; 268:21212-7.

22. Giangreco A, Reynolds SD, Stripp BR. Terminal bronchioles harbor a unique airway stem cell population that localizes to the bronchoalveolar duct junction. Am J Pathol 2002;161:173-82.

23. Montesano R, Matsumoto K, Nakamura T, 
Orci L. Identification of a fibroblastderived epithelial morphogen as hepatocyte growth factor. Cell 1991;67:901-8.

24. Ohmichi H, Koshimizu U, Matsumoto K, Nakamura T. Hepatocyte growth factor (HGF) acts as a mesenchyme-derived morphogenic factor during fetal lung development. Development 1998;125:1315-24.

25. Kato T, Oka K, Nakamura T, Ito A. Bronchioalveolar morphogenesis of human bronchial epithelial cells depending upon hepatocyte growth factor. J Cell
Mol Med 2015;19:2818-26.

26. Lee JH, Bhang DH, Beede A, Huang TL, Stripp BR, Bloch KD, et al. Lung stem cell differentiation in mice directed by endothelial cells via a BMP4-NFATc1-thrombospondin-1 axis. Cell 2014;156:440-55.

27. Sakamaki Y, Matsumoto K, Mizuno S, Miyoshi S, Matsuda H, Nakamura T. Hepatocyte growth factor stimulates proliferation of respiratory epithelial cells during postpneumonectomy compensatory lung growth in mice. Am J Respir Cell Mol
Biol 2002;26:525-33.

28. Shigemura N, Sawa Y, Mizuno S, Ono M, Ohta M, Nakamura T, et al. Amelioration of pulmonary emphysema by in vivo gene transfection with hepatocyte growth factor in rats. Circulation 2005;111:1407-14.

29. Yamamoto H, Yun EJ, Gerber HP, Ferrara N, Whitsett JA, Vu TH. Epithelial-vascular cross talk mediated by VEGF-A and HGF signaling directs primary septae formation during distal lung morphogenesis. Dev Biol 2007;308:44-53. 